\title{
Recruitment manoeuvres in acute lung injury/acute respiratory distress syndrome
}

\author{
I. Morán*, E. Zavala\#, R. Fernández", L. Blanch", J. Mancebo*
}

Recruitment manoeuvres in acute lung injurylacute respiratory distress syndrome. I. Morán, E. Zavala, R. Fernández, L. Blanch, J. Mancebo. (C)ERS Journals Ltd 2003. ABSTRACT: Acute respiratory distress syndrome/acute lung injury is characterised by profound hypoxaemia due to a permeability pulmonary oedema.

In this setting, recruitment manoeuvres (RMs) can be a useful tool as adjuncts to lung protective ventilatory strategies to prevent cyclic alveolar stress and avoid alveolar collapse.

Many experimental and physiological studies have discussed the use of RMs but only a few heterogeneous clinical experiences have demonstrated the beneficial and deleterious effects that can occur using these manoeuvres. Besides, a lot of questions remain to be answered to find the best way to perform optimal RMs.

Further experimental and clinical trials are needed to understand the potential beneficial effects of recruitment manoeuvres when using a protective mechanical ventilation strategy. This paper is a general review of experimental works that support application of recruitment manoeuvres emphasising the clinical studies that have been published to date in acute respiratory distress syndrome patients. Eur Respir J 2003; 22: Suppl. 42, 37s-42s.
*Intensive Care Service Hospital de la Santa Creu i Sant Pau, and " ${ }^{\#}$ Surgical Intensive Care Unit Hospital Clínic, Barcelona, Spain. Critical Care Center Hospital de Sabadell Corporacio Sanitaria Parc Taulí, Sabadell, Spain.

Correspondence: J. Mancebo, Servei de Medicina Intensiva Hospital de la Santa Creu i Sant Pau, Sant Antoni M Claret, 167, Barcelona 08025, Spain.

Fax: 34932919280

E-mail: jmancebo@hsp.santpau.es

Keywords: Acute lung injury, acute respiratory distress syndrome, lung protective strategy, mechanical ventilation, positive end-expiratory pressure
Abnormalities that occur in patients with acute lung injury (ALI) or acute respiratory distress syndrome (ARDS) are mainly alveolar flooding, alveolar collapse and loss of aerated lung volume. These alterations cause ventilation-perfusion heterogeneity and an increase in intrapulmonary shunt, which worsens arterial and tissue oxygenation.

Mechanical ventilation can produce lung damage that is indistinguishable from the pulmonary alterations caused by ARDS itself and may contribute to mortality in ARDS patients. Alveolar overdistention, cyclic collapse and re-inflation of alveolar units with tidal breathing are major factors contributing to further lung damage. DREYFUSS and SAUMON [1] emphasised the idea that the main determinant of "volutrauma" seems to be the end-inspiratory volume that causes excessive tissue stretching. These investigators suggested that the risk of volutrauma in the lungs of ARDS patients lie in the most compliant ventilated regions as they could be overdistended, whereas the collapsed areas are relatively protected.

Lung-protective strategies during mechanical ventilation have been proposed for ARDS patients. Such strategies try to avoid high alveolar pressures by using small tidal volumes $(V \mathrm{~T})$ and attempt to keep alveoli open at end expiration with sufficient positive end-expiratory pressure (PEEP) [2-5]. Recent clinical trials in patients with ALI or ARDS have demonstrated that lung-protective strategies led to improvements in clinical outcomes [3,5]. Vascular pressures and flow can also play a role in oedema formation, and it has been shown that lung injury can be significantly decreased in a fixed mechanical ventilation model, if pulmonary vascular pressures are strictly limited [6,7].

It is essential to know the internal mechanism of the heterogeneous distribution of regional atelectasis, lung tissue damage, oedema formation and inflammatory response in
ARDS patients undergoing mechanical ventilation. Indeed, many studies have attempted to explain the effects of the ventilator on regional lung structure and mechanical function in ARDS patients. Since the pioneering studies [8-11] it is known that the entire lung volume is considerably reduced, and the distribution of regional atelectasis is irregular in the early phase of ARDS. These studies reinforced the idea that many areas of an injured lung are derecruited [11,12] and such findings are the basis of the "baby lung" concept.

If mechanical ventilation perpetuates cyclic opening and closing of alveoli and if high pressure is applied repeatedly in previous expanding units, these induce lung injury. Mechanisms explaining lung damage include: tangential shearing forces that produce stress on the alveoli wall, sustain epithelial and endothelial damage in such a way that capillary stress fractures and eventually haemorrhagic oedema may occur [6, 13].

In a post mortem analysis, RouBY et al. [14] found alveolar overdistention and/or intraparenchymal pseudocysts in a group of ARDS patients who were ventilated with high $V \mathrm{~T}$ $\left(12 \mathrm{~mL} \cdot \mathrm{kg}^{-1}\right)$ and high airway pressures. MUSCEDERE et al. [15] explain barotrauma as the result of mechanical factors. They observed epithelial lesions in alveolar ducts and small airways in an ex vivo lung rat model, after ventilating lungs with a PEEP level below the lower inflation point (LIP) of the pressure/volume $(P / V)$ curve. This PEEP below LIP did not avoid cyclic opening and closing in determined alveolar units. On the contrary, when a PEEP level above LIP was applied, a marked decrease in lung damage was observed.

Similar data were found by GATTINONI et al. [16] using chest computed tomography (CT) scans in patients at different ARDS stages. These authors also observed histological signs of airspace enlargement. There was a significant increase in the number of bullae at the hilium and in the basal 
parts of the lungs in patients with intermediate or late phase ARDS. Furthermore, lung lesions were less evident at the apex. Cyclic opening and closing at the dependent parts of the ARDS lung may explain these data. The same group attributed the atelectasis observed in the dependent parts of the lung to the increased lung weight and oedema formation, and suggested that PEEP should be adjusted to the level needed to reopen collapsed airways and alveoli $[8,9]$.

Several groups of investigators have demonstrated the role of inflammatory mediators in the pathophysiology of multisystem organ failure and shock [1]. There is considerable evidence suggesting that mechanical ventilation may contribute to the initiation and propagation of a systemic inflammatory response. TREMBLAY et al. [17] observed an increase in the level of cytokines and c-fos messenger ribonucleic acid expression in an ex vivo nonperfused lung rat model ventilating at high transpulmonary pressure with zero PEEP.

The same experimental model was used by RANIERI et al. [18] to study the effect of PEEP on inflammatory mediator release using $P / V$ curves to adjust a noninjurious ventilatory strategy. In a previous randomised controlled trial, the same investigators described the effect of protective mechanical ventilation on reducing inflammatory mediators in patients with ARDS [4].

Additionally, in experimental models of lung infection, overdistention and cyclic collapse ventilatory strategies have demonstrated the effect of mechanical ventilation on bacterial and endotoxin translocation from the alveoli to the bloodstream. Applying a moderate PEEP level can significantly reduce these effects even at the same transpulmonary pressure at end inspiration [19-21].

SLUTSKY and TREMBLAY [22] and SLUTSKY [23] emphasised the relationships between mechanical ventilation and multiple organ failure [22] and coined the term "biotrauma", a complex concept that combines the relationship between pulmonary mechanics, histopathology, oedema formation, mechanotransduction and inflammation in ARDS [23].

In a recent review, HUBMAYR [24] discussed two hypotheses that emphasised the distinction between oedema and collapse. In the first of these, oedema fluid and foam fill dependent regions in the wet lung, and the pressure in the airways is required to drive foam out and inflate alveoli with high surface tension. In the second hypothesis the mechanisms of collapse and atelectasis in dependent parts of the wet lung are an increased weight in these regions, and the pressure that is applied is used to open collapsed airways. HUBMAYR [24] pointed out the intimate relationship between alveolar damage and cell response to the mechanical stress induced by mechanical ventilation.

In short, all of these studies indicate the importance of preventing lung collapse or oedema formation and suggest the implementation of ventilatory strategies with small $V \mathrm{~T}$ and PEEP [3, 5, 25].

\section{Experimental studies that support recruitment manoeuvres}

Many experimental studies support the use of alveolar recruitment manoeuvres (RM) in surfactant depletion and in saline lavage models [26-30]. In an animal model of saline lavage induced ALI, BOND et al. [26], found an improvement in the respiratory system compliance and arterial oxygenation during high frequency oscillatory ventilation after performing RMs. This only happened when the animals were ventilated with low $V \mathrm{~T}$ and zero end expiratory pressure.

In a similar model, RIMENSBERGER and co-workers [31, 32] compared the effects of a single RM when PEEP was below the LIP of the $P / V$ curve, and the effects of PEEP above the LIP but without RM. Their results showed a better oxygenation and no increase on histological lung damage when applying the first strategy. The same group described the beneficial effects on oxygenation, on static lung compliance and lung volume during ventilation that were reached by means of single sustained RM (PEEP $30 \mathrm{cmH}_{2} \mathrm{O}$ ).

Some data suggest that RMs have different effects determined by the type of lung insult. VAN DER KLOOT et al. [33] studied the effects of RMs on gas exchange and lung volumes in three experimental models of ALI; saline lavage, oleic acid and pneumonia. Only in the surfactant depletion model did oxygenation improve when RM was performed. This occurred when PEEP below LIP and low $V$ T was used. No benefit from RMs was observed in any model when $V \mathrm{~T}$ or PEEP level was set above LIP.

LU et al. [34] demonstrated that the application of an RM after endotracheal suctioning completely reversed the atelectasis, the bronchoconstriction and the decrease in arterial oxygen saturation which were observed after endotracheal suctioning in an anaesthetised sheep model.

Other studies underscore the importance of body posture (supine or prone) on regional distribution of intrapulmonary ventilation and perfusion [35]. CAKAR et al. [36] showed similar data and a better oxygenation response to RMs during prone position in comparison to supine, in an oleic acidinduced lung injury model. The beneficial effects on arterial blood gases were sustained over time in prone position and with a lower PEEP level than in supine position.

The optimal airway pressure to be applied during RMs has been evaluated in mathematical and experimental studies [37-39]. These models have demonstrated that alveolar recruitment is completed during tidal inflation and reaches the maximum volume at airway pressures $>40 \mathrm{cmH}_{2} \mathrm{O}$. Similar data have been reported by CROTTI et al. [40], who performed thoracic CT scans at different PEEP levels and plateau pressures (maximal PEEP: $20 \mathrm{cmH}_{2} \mathrm{O}$, maximal plateau pressure $45 \mathrm{cmH}_{2} \mathrm{O}$ ). They found that alveolar recruitment occurred along the entire $P / V$ curve, independently of the lower and upper inflection point, and was progressive from nondependent to dependent lung parts.

\section{Recruitment manoeuvres in patients: what has been learnt to date?}

Very few works on clinical practice have studied the effects of RMs in ALI/ARDS patients. ROTHEN and coworkers [41-43] made important contributions in different studies focusing on atelectasis induced by anaesthesia in surgical patients. By means of chest CT scans, they described lung re-expansion by applying a vital capacity manoeuvre or by an inflation pressure of $40 \mathrm{cmH}_{2} \mathrm{O}$ and showed that greater reduction in collapsed lung can be observed during the first seconds of the vital capacity manoeuvre [41-43].

Various groups have described the important role of composition of inspiratory gas on alveolar collapse. Several factors, including the use of high inspiratory oxygen fraction $\left(\mathrm{FI}, \mathrm{O}_{2}\right)$ in alveolar units with a low ventilation-perfusion ratio, may promote denitrogenation atelectasis in ARDS patients [42, 44]. This finding indicates the possible role of reabsorption phenomena in the recurrence of collapse in previously reexpanded atelectatic lung that is ventilated with high $F \mathrm{I}, \mathrm{O}_{2}$.

PELOSI et al. [45] applied three consecutive sighs per minute at $45 \mathrm{cmH}_{2} \mathrm{O}$ of plateau pressure for $1 \mathrm{~h}\left(\mathrm{PEEP} 14 \pm 2.2 \mathrm{cmH}_{2} \mathrm{O}\right)$ in patients ventilated with a protective strategy. They found a marked decrease in intrapulmonary shunt and a significant 
increase in end-expiratory lung volume. The latter was correlated with the improvement in arterial oxygenation.

FOTI et al. [46] applied continuous positive pressure ventilation RM over low PEEP level ventilation strategy in 15 PEEP-responder ARDS patients. These authors observed significantly improved oxygenation and alveolar recruitment compared to patients with low PEEP without RMs (continuous positive pressure ventilation at low positive endexpiratory pressure level (CPPVlo): mean PEEP $9 \pm 3 \mathrm{cmH}_{2} \mathrm{O}$ ). Most important, they found a better oxygenation after applying a continuous high PEEP level (mean PEEP 16士2) than after performing RMs above CPPVlo. These data suggest that continuous high PEEP level keeps alveoli opened and prevents lung derecruitment between intermittent RMs. However, periodic tidal recruitment and derecruitment may produce ventilator-associated lung injury.

An alternative method for RM performance are sustained lung inflations with continuous positive airway pressure (CPAP). LAPINSKY et al. [47] applied sustained high pressure RMs (30-45 $\mathrm{cm} \mathrm{H}_{2} \mathrm{O}$ for $20 \mathrm{~s}$ ) and found a significant improvement in arterial oxygenation. Hypotension occurred in some patients during the inflation manoeuvre, but blood pressure rapidly normalised after inflation. The beneficial effects of the $\mathrm{RM}$ were lost during the $4 \mathrm{~h}$ follow-up in 4 of 14 patients. This response was attributed to basal PEEP levels that were insufficient to maintain the lung opened. LIM et al. [48] used an "extended sigh" in ARDS patients. From the baseline ( $V \mathrm{~T}$ $8 \mathrm{~mL} \cdot \mathrm{kg}^{-1}$ and PEEP $\left.10 \mathrm{cmH}_{2} \mathrm{O}\right)$ in volume control ventilation mode, they changed the $V$ T-PEEP values to $6 \mathrm{~mL} \cdot \mathrm{kg}^{-1}$ $15 \mathrm{cmH}_{2} \mathrm{O}, 4 \mathrm{~mL} \cdot \mathrm{kg}^{-1}-20 \mathrm{cmH}_{2} \mathrm{O}$, and $2 \mathrm{~mL} \cdot \mathrm{kg}^{-1}-25 \mathrm{cmH}_{2} \mathrm{O}$, consecutively, each $30 \mathrm{~s}$. After VT-PEEP $2 \mathrm{~mL} \cdot \mathrm{kg}^{-1}-25 \mathrm{cmH}_{2} \mathrm{O}$, the ventilation model was switched to CPAP of $30 \mathrm{cmH}_{2} \mathrm{O}$ for $30 \mathrm{~s}$. This study showed an improvement in arterial oxygenation which was persistent $1 \mathrm{~h}$ after the application of the extended sigh. No major haemodynamic or respiratory complications were encountered.

RICHARD et al. [49] analysed the role of $V \mathrm{~T}$ and PEEP on alveolar recruitment. The authors demonstrated a decrease in oxygenation in 10 of 15 patients when $V \mathrm{~T}$ was switched from 10 to $6 \mathrm{~mL} \cdot \mathrm{kg}^{-1}$ with PEEP at or above the LIP. This alveolar derecruitment was prevented by increasing PEEP over LIP or transiently reversed by RMs (fig. 1).

RMs performed after endotracheal suctioning may represent one of the most interesting examples of the potential beneficial effects on a previous derecruited lung. Two groups have described advantages of a closed system of endotracheal suctioning performed without disconnection from the ventilator $[50,51]$. A closed system allows a lower lung volume drop and a faster volume recuperation and prevents hypoxaemia in patients with an increased tendency to alveolar collapse. RMs have been proposed after patients are disconnected from the ventilator and after suctioning lung secretions [34].

However, recent studies [52] suggest that the effects of RMs in ALI/ARDS patients who are ventilated with low $V \mathrm{~T}$ and high PEEP levels are not effective for sustained recruitment. Besides, haemodynamic alterations may limit their use. Similar data were reported by VILLAGRA et al. [53]. These authors found a variable response to RMs and suggested that RMs applied to patients with ARDS ventilated with a lung protective strategy were not effective in improving arterial oxygenation in the majority of cases. These authors also reported that intrapulmonary shunt increased during RMs and attributed this finding to a redistribution of blood flow to nonventilated areas due to the alveolar overdistention of ventilated areas induced by the RMs.

Preliminary data from the current author's group [54] showed significant beneficial effects of a RM on arterial blood gases in 11 ARDS patients mechanically ventilated with an Acute Respiratory Distress Syndrome clinical Network (ARDSnet) strategy. RMs were performed by stepwise increases of PEEP and plateau pressure up to PEEP $40 \mathrm{cmH}_{2} \mathrm{O}$ and plateau pressure $60 \mathrm{cmH}_{2} \mathrm{O}$ (fig. 2). Arterial blood gas improvement was sustained over time $(2 \mathrm{~h})$.

Conversely, other studies found marked decreases in intrapulmonary shunt $[45,55]$. In eight patients with early ARDS, MANCINI et al. [55] showed an improvement in arterial oxygen tension $\left(\mathrm{Pa}, \mathrm{O}_{2}\right)$ and a significant decrease in intrapulmonary shunt. They suggested that a protective ventilatory strategy combining low $V \mathrm{~T}$ and high PEEP level above the LIP was the pivotal mechanism to account for improvement in arterial oxygenation by means of recruitment of previously collapsed alveoli and redistribution of pulmonary blood flow from nonventilated alveoli to newly aerated units [55].

More recently, GRASSO et al. [56] applied $40 \mathrm{cmH}_{2} \mathrm{O}$ of CPAP for $40 \mathrm{~s}$ and defined the patients as RM-responders when arterial oxygenation increased $\geqslant 50 \%$ over baseline. Their data suggested that RMs significantly improved arterial oxygenation only in patients with early ARDS and without impairment of chest wall mechanics. These authors suggested that a low static lung elastance could be a marker of the

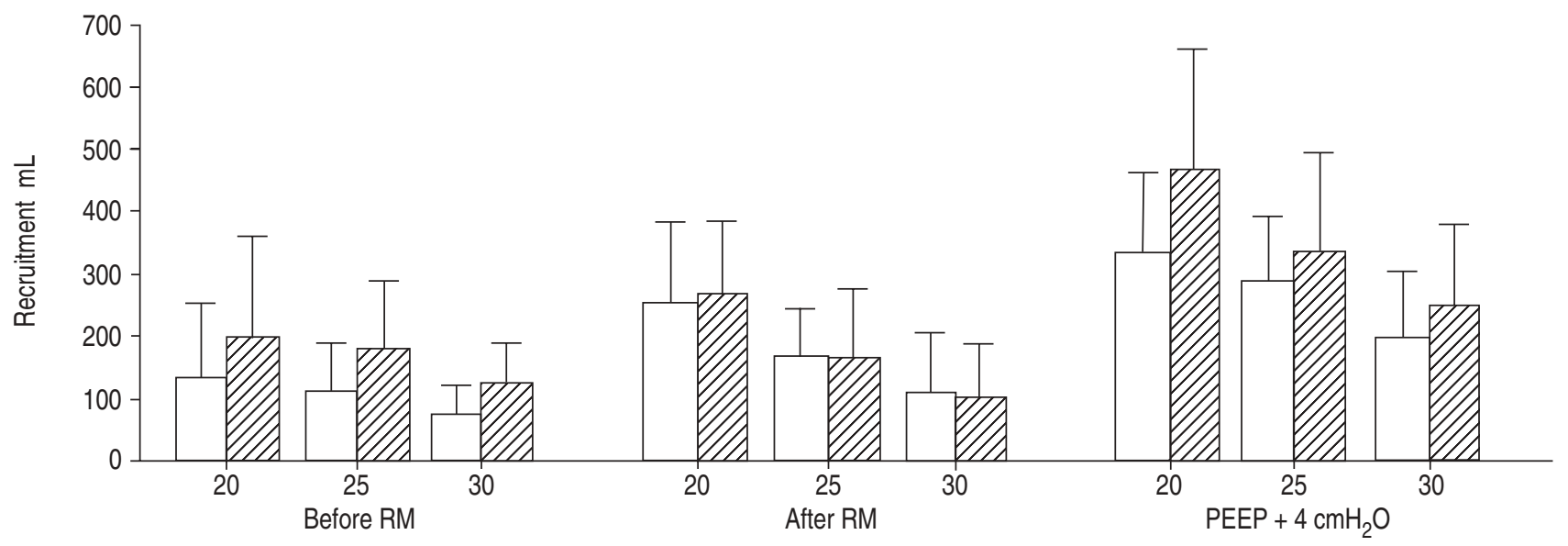

Fig. 1.-Effects of tidal volume $\left(V_{\mathrm{T}}\right)$ and positive end-expiratory pressure (PEEP) on recruited volume. When $V_{\mathrm{T}}$ is low and PEEP is set at lower inflation point (LIP) there is a derecruitment in comparison with high $V \mathrm{~T}$ (before $\mathrm{RM}$ ). A recruitment manoeuvre (RM) is useful in this scenario (after RM). When a PEEP level $4 \mathrm{cmH}_{2} \mathrm{O}$ above LIP is used $\left(\mathrm{PEEP}+4 \mathrm{cmH}_{2} \mathrm{O}\right)$, the recruited volume is maximised and no $V \mathrm{~T}$ effects are seen. $\square$ : low $V \mathrm{~T} ; \mathbb{Z}$ : conventional $V_{\mathrm{T}}$. Reproduced with permission from [49]. 


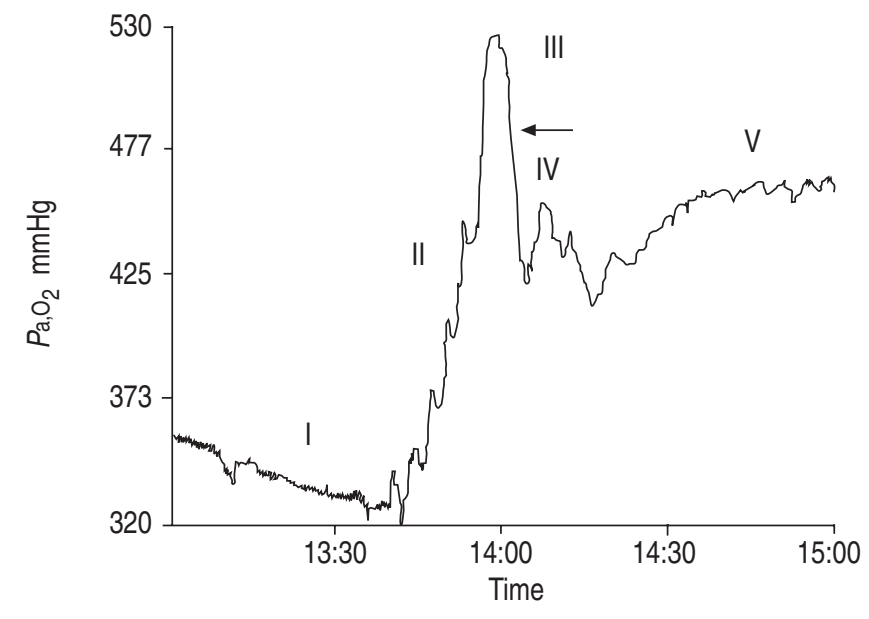

Fig. 2.-Original recording of continuous arterial oxygen tension $\left(P \mathrm{a}, \mathrm{O}_{2}\right)$ monitoring with an intra-arterial catheter in an early acute respiratory distress syndrome (ARDS) patient with abdominal sepsis. I) Basal: mechanical ventilation with the Acute Respiratory Distress Syndrome Network (ARDSnet) National Institutes of Health (NIH) strategy (inspiratory oxygen fraction $\left(F \mathrm{I}, \mathrm{O}_{2}\right) 0.7$; positive end-expiratory pressure (PEEP) $10 \mathrm{cmH}_{2} \mathrm{O}$ ). $F \mathrm{I}_{1} \mathrm{O}_{2} 1$ was used to perform the manoeuvre. II) Progressive increase in $\mathrm{Pa}_{\mathrm{a}} \mathrm{O}_{2}$ during a 15 min duration. A PEEP $40 \mathrm{cmH}_{2} \mathrm{O}$ and plateau pressure $60 \mathrm{cmH}_{2} \mathrm{O}$ were reached. $\mathrm{Pa}_{\mathrm{a}} \mathrm{O}_{2}$ increased up to $520 \mathrm{mmHg}$. III) Gradual decreases of PEEP ( $2 \mathrm{cmH}_{2} \mathrm{O}$ every $4 \mathrm{~min}$ ) to find alveolar collapsing pressure (PEEP 13 in this patient, marked with an arrow). Collapsing pressure was defined as decrease in $\mathrm{Pa}, \mathrm{O}_{2}>10 \%$ with respect to maximal $\mathrm{Pa}, \mathrm{O}_{2}$. IV) The collapsed units were reopened with a new 1-min duration RM (plateau pressure (PP)/PEEP $60 / 40 \mathrm{mmHg}$ respectively), then a PEEP level $2 \mathrm{cmH}_{2} \mathrm{O}$ higher than collapsing pressure was applied $\left(15 \mathrm{cmH}_{2} \mathrm{O}\right)$. V) Same ventilatory parameters as I, except for a PEEP set at $15 \mathrm{cmH}_{2} \mathrm{O}$. Effects on $\mathrm{Pa}_{\mathrm{a}} \mathrm{O}_{2}$ were sustained over time.

potential for recruitment. Cardiac output and mean arterial pressure markedly decreased in nonresponders, although it returned to baseline within 20-30 s after RMs.

PATRONITI et al. [57] applied one sigh per minute to baseline pressure support ventilation (PSV) in patients with early ARDS. Sigh was performed by means of a CPAP level $20 \%$ higher than the plateau pressure of the PSV breaths or, at least $35 \mathrm{cmH}_{2} \mathrm{O}$. They observed a significant improvement in arterial oxygenation associated to an increase in endexpiratory lung volume and respiratory system compliance during the sigh period, thus suggesting that sighs promote alveolar recruitment. These changes returned to baseline after sighs were discontinued.

Looking for side-effects of RMs, BEIN et al. [58] analysed the impact of RMs on intracranial pressure (ICP) and cerebral metabolism in patients with acute cerebral injury and respiratory failure. They performed a progressive increase in peak pressure up to $60 \mathrm{cmH}_{2} \mathrm{O}$. The pressure was then maintained for $30 \mathrm{~s}$. An increase of ICP was found at the end of RMs and mean arterial pressure was reduced, with the resulting decrease of cerebral perfusion pressure $(72 \pm 8$ versus $60 \pm 10 \mathrm{mmHg}$ ). Jugular venous oxygen saturation deteriorated at the end of the procedure ( $69 \pm 6$ versus $59 \pm 7 \%)$ but arterial minus jugular venous lactate content difference remained unchanged. Ten minutes after RMs, all the haemodynamic and cerebral parameters were normalised and improvement on arterial oxygenation disappeared.

\section{Conclusions}

Experimental models and physiological studies have just established the principles to understand the potential beneficial effects of RMs in ARDS patients who are ventilated with a protective strategy. Nevertheless many questions still need to be answered. The clinicians need more information about many aspects of these manoeuvres; namely, the optimal time to perform RMs (first hours after endotracheal intubation, early phase of ARDS, after endotracheal suctioning, etc.), how often they should be used, their duration and the recommended ventilatory mode (CPAP, sighs, pressure controlled ventilation, short duration high PEEP level). Moreover, the long-lasting effects of RMs on arterial blood gases are contradictory.

Furthermore, clinicians cannot ignore possible deleterious effects such as barotrauma and increases in intrapulmonary shunt when RMs result only in overdistension of already ventilated lung regions. Major haemodynamic side-effects (decrease on cardiac output, increase on pulmonary arterial pressure and end-diastolic right ventricular pressure, severe hypotension, bradycardia) may occur during or just after RMs are applied. In addition, direct effects of RMs on alveolar cells, via mechanotransduction pathways, might also induce further lung damage.

Further studies are needed to clinically evaluate the potential beneficial effects of the different types of recruitment manoeuvres that could be included into protective mechanical ventilation strategies.

\section{References}

1. Dreyfuss D, Saumon G. Ventilator-induced lung injury: lessons from experimental studies. Am J Respir Crit Care Med 1998; 157: 294-323.

2. International consensus conferences in intensive care medicine. Ventilator-associated lung injury in ARDS. American Thoracic Society, European Society of Intensive Care Medicine, Societe de Reanimation Langue Francaise. Intensive Care Med 1999; 25: 1444-1452.

3. Amato MB, Barbas CS, Medeiros DM, et al. Effect of a protective-ventilation strategy on mortality in the acute respiratory distress syndrome. N Engl J Med 1998; 338: 347354.

4. Ranieri VM, Suter PM, Tortorella C, et al. Effect of mechanical ventilation on inflammatory mediators in patients with acute respiratory distress syndrome: a randomized controlled trial. JAMA 1999; 282: 54-61.

5. Ventilation with lower tidal volumes as compared with traditional tidal volumes for acute lung injury and the acute respiratory distress syndrome. The Acute Respiratory Distress Syndrome Network. N Engl J Med 2000; 342: 1301-1308.

6. Hotchkiss JR, Jr, Blanch L, Naveira A, et al. Relative roles of vascular and airspace pressures in ventilator-induced lung injury. Crit Care Med 2001; 29: 1593-1598.

7. Hotchkiss JR, Jr, Blanch L, Murias G, et al. Effects of decreased respiratory frequency on ventilator-induced lung injury. Am J Respir Crit Care Med 2000; 161: 463-468.

8. Gattinoni L, D'Andrea L, Pelosi P, Vitale G, Pesenti A, Fumagalli R. Regional effects and mechanism of positive end-expiratory pressure in early adult respiratory distress syndrome. JAMA 1993; 269: 2122-2127.

9. Gattinoni L, Pelosi P, Crotti S, Valenza F. Effects of positive end-expiratory pressure on regional distribution of tidal volume and recruitment in adult respiratory distress syndrome. Am J Respir Crit Care Med 1995; 151: 1807-1814.

10. Gattinoni L, Pesenti A, Avalli L, Rossi F, Bombino M. Pressure-volume curve of total respiratory system in acute respiratory failure. Computed tomographic scan study. Am Rev Respir Dis 1987; 136: 730-736.

11. Pelosi P, D'Andrea L, Vitale G, Pesenti A, Gattinoni L. Vertical gradient of regional lung inflation in adult respiratory distress syndrome. Am J Respir Crit Care Med 1994; 149: 813. 
12. Puybasset L, Cluzel P, Chao N, Slutsky AS, Coriat P, Rouby JJ. A computed tomography scan assessment of regional lung volume in acute lung injury. The CT Scan ARDS Study Group. Am J Respir Crit Care Med 1998; 158: $1644-1655$.

13. Marini JJ, Wheeler AP. Critical care medicine: the essentials. 2nd edition. Baltimore, Williams \& Wilkins, 1997; pp. 136156.

14. Rouby JJ, Lherm T, Martin de Lassale E, et al. Histologic aspects of pulmonary barotrauma in critically ill patients with acute respiratory failure. Intensive Care Med 1993; 19: 383-389.

15. Muscedere JG, Mullen JB, Gan K, Slutsky AS. Tidal ventilation at low airway pressures can augment lung injury. Am J Respir Crit Care Med 1994; 149: 1327-1334.

16. Gattinoni L, Bombino M, Pelosi P, et al. Lung structure and function in different stages of severe adult respiratory distress syndrome. JAMA 1994; 271: 1772-1779.

17. Tremblay L, Valenza F, Ribeiro SP, Li J, Slutsky AS. Injurious ventilatory strategies increase cytokines and c-fos m-RNA expression in an isolated rat lung model. $J$ Clin Invest 1997; 99: 944-952.

18. Ranieri VM, Zhang H, Mascia L, et al. Pressure-time curve predicts minimally injurious ventilatory strategy in an isolated rat lung model. Anesthesiology 2000; 93: 1320-1328.

19. Nahum A, Hoyt J, Schmitz L, Moody J, Shapiro R, Marini JJ. Effect of mechanical ventilation strategy on dissemination of intratracheally instilled Escherichia coli in dogs. Crit Care Med 1997; 25: 1733-1743.

20. Murphy DB, Cregg N, Tremblay L, et al. Adverse ventilatory strategy causes pulmonary-to-systemic translocation of endotoxin. Am J Respir Crit Care Med 2000; 162: 27-33.

21. Verbrugge SJ, Sorm V, van't Veen A, Mouton JW, Gommers D, Lachmann B. Lung overinflation without positive end-expiratory pressure promotes bacteremia after experimental Klebsiella pneumoniae inoculation. Intensive Care Med 1998; 24: 172-177.

22. Slutsky AS, Tremblay LN. Multiple system organ failure. Is mechanical ventilation a contributing factor? Am J Respir Crit Care Med 1998; 157: 1721-1725.

23. Slutsky AS. Basic science in ventilator-induced lung injury: implications for the bedside. Am J Respir Crit Care Med 2001; 163: 599-600.

24. Hubmayr RD. Perspective on lung injury and recruitment: a skeptical look at the opening and collapse story. Am J Respir Crit Care Med 2002; 165: 1647-1653.

25. Artigas A, Bernard GR, Carlet J, et al. The AmericanEuropean Consensus Conference on ARDS, part 2. Ventilatory, pharmacologic, supportive therapy, study design strategies and issues related to recovery and remodeling. Intensive Care Med 1998; 24: 378-398.

26. Bond DM, McAloon J, Froese AB. Sustained inflations improve respiratory compliance during high-frequency oscillatory ventilation but not during large tidal volume positivepressure ventilation in rabbits. Crit Care Med 1994; 22: 1269-1277.

27. Kolton M, Cattran CB, Kent G, Volgyesi G, Froese AB, Bryan AC. Oxygenation during high-frequency ventilation compared with conventional mechanical ventilation in two models of lung injury. Anesth Analg 1982; 61: 323-332.

28. McCulloch PR, Forkert PG, Froese AB. Lung volume maintenance prevents lung injury during high frequency oscillatory ventilation in surfactant-deficient rabbits. Am Rev Respir Dis 1988; 137: 1185-1192.

29. Rimensberger PC, Pache JC, McKerlie C, Frndova H, Cox PN. Lung recruitment and lung volume maintenance: a strategy for improving oxygenation and preventing lung injury during both conventional mechanical ventilation and high-frequency oscillation. Intensive Care Med 2000; 26: 745755.

30. Vazquez de Anda GF, Hartog A, Verbrugge SJ, Gommers D, Lachmann B. The open lung concept: pressure-controlled ventilation is as effective as high-frequency oscillatory ventilation in improving gas exchange and lung mechanics in surfactant-deficient animals. Intensive Care Med 1999; 25: 990-996.

31. Rimensberger PC, Pristine G, Mullen BM, Cox PN, Slutsky AS Lung recruitment during small tidal volume ventilation allows minimal positive end-expiratory pressure without augmenting lung injury. Crit Care Med 1999; 27: 1940-1945.

32. Rimensberger PC, Cox PN, Frndova H, Bryan AC. The open lung during small tidal volume ventilation: concepts of recruitment and "optimal" positive end-expiratory pressure. Crit Care Med 1999; 27: 1946-1952.

33. Van der Kloot TE, Blanch L, Youngblood AM, et al. Recruitment maneuvers in three experimental models of acute lung injury. Effect on lung volume and gas exchange. Am J Respir Crit Care Med 2000; 161: 1485-1494.

34. Lu Q, Capderou A, Cluzel P, et al. A computed tomographic scan assessment of endotracheal suctioning-induced bronchoconstriction in ventilated sheep. Am J Respir Crit Care Med 2000; 162: 1898-1904.

35. Pelosi $\mathrm{P}$, Tubiolo $\mathrm{D}$, Mascheroni $\mathrm{D}$, et al. Effects of the prone position on respiratory mechanics and gas exchange during acute lung injury. Am J Respir Crit Care Med 1998; 157: 387-393.

36. Cakar N, der Kloot TV, Youngblood M, Adams A, Nahum A. Oxygenation response to a recruitment maneuver during supine and prone positions in an oleic acid-induced lung injury model. Am J Respir Crit Care Med 2000; 161: 19491956.

37. Hickling KG. The pressure-volume curve is greatly modified by recruitment. A mathematical model of ARDS lungs. Am J Respir Crit Care Med 1998; 158: 194-202.

38. Hickling KG. Best compliance during a decremental, but not incremental, positive end-expiratory pressure trial is related to open-lung positive end-expiratory pressure: a mathematical model of acute respiratory distress syndrome lungs. Am J Respir Crit Care Med 2001; 163: 69-78.

39. Pelosi P, Goldner M, McKibben A, et al. Recruitment and derecruitment during acute respiratory failure: an experimental study. Am J Respir Crit Care Med 2001; 164: 122130.

40. Crotti S, Mascheroni D, Caironi P, et al. Recruitment and derecruitment during acute respiratory failure: a clinical study. Am J Respir Crit Care Med 2001; 164: 131-140.

41. Rothen HU, Sporre B, Engberg G, Wegenius G, Hedenstierna G. Re-expansion of atelectasis during general anaesthesia: a computed tomography study. $\mathrm{Br} J$ Anaesth 1993; 71: 788-795.

42. Rothen HU, Sporre B, Engberg G, Wegenius G, Hedenstierna G. Reexpansion of atelectasis during general anaesthesia may have a prolonged effect. Acta Anaesthesiol Scand 1995; 39: 118-125.

43. Rothen HU, Neumann P, Berglund JE, Valtysson J, Magnusson A, Hedenstierna G. Dynamics of re-expansion of atelectasis during general anaesthesia. Br J Anaesth 1999; 82: $551-556$

44. Santos C, Ferrer M, Roca J, Torres A, Hernandez C, Rodriguez-Roisin R. Pulmonary gas exchange response to oxygen breathing in acute lung injury. Am J Respir Crit Care Med 2000; 161: 26-31.

45. Pelosi $\mathrm{P}$, Cadringher $\mathrm{P}$, Bottino $\mathrm{N}$, et al. Sigh in acute respiratory distress syndrome. Am J Respir Crit Care Med 1999; 159: 872-880.

46. Foti G, Cereda M, Sparacino ME, De Marchi L, Villa F, Pesenti A. Effects of periodic lung recruitment maneuvers on gas exchange and respiratory mechanics in mechanically ventilated acute respiratory distress syndrome (ARDS) patients. Intensive Care Med 2000; 26: 501-507.

47. Lapinsky SE, Aubin M, Mehta S, Boiteau P, Slutsky AS. Safety and efficacy of a sustained inflation for alveolar recruitment in adults with respiratory failure. Intensive Care Med 1999; 25: 1297-1301. 
48. Lim CM, Koh Y, Park W, et al. Mechanistic scheme and effect of "extended sigh" as a recruitment maneuver in patients with acute respiratory distress syndrome: a preliminary study. Crit Care Med 2001; 29: 1255-1260.

49. Richard JC, Maggiore SM, Jonson B, Mancebo J, Lemaire F, Brochard L. Influence of tidal volume on alveolar recruitment. Respective role of PEEP and a recruitment maneuver. Am J Respir Crit Care Med 2001; 163: 1609-1613.

50. Cereda M, Villa F, Colombo E, Greco G, Nacoti M, Pesenti A. Closed system endotracheal suctioning maintains lung volume during volume-controlled mechanical ventilation. Intensive Care Med 2001; 27: 648-654.

51. Maggiore SM, Lellouche F, Pigeot J, et al. Prevention of endotracheal suctioning-induced alveolar derecruitment in acute lung injury. Am J Respir Crit Care Med 2003; 167: $1215-1224$.

52. Brower RG, Clemmer $\mathrm{T}$, Lanken $\mathrm{P}$, et al. Effects of recruitment maneuvers on acute lung injury patients ventilated with lower tidal volumes and higher positive end-expiratory pressures. Am J Respir Crit Care Med 2001; 163: A767.

53. Villagra A, Ochagavia A, Vatua S, et al. Recruitment maneuvers during lung protective ventilation in acute respiratory distress syndrome. Am J Respir Crit Care Med 2002; 165: 165-170.

54. Morán I, Mancebo J, Suárez F, et al. Effects of recruitment maneuvers in patients with ARDS. Am J Respir Crit Care Med 2002; 163: B31.

55. Mancini M, Zavala E, Mancebo J, et al. Mechanisms of pulmonary gas exchange improvement during a protective ventilatory strategy in acute respiratory distress syndrome. Am J Respir Crit Care Med 2001; 164: 1448-1453.

56. Grasso S, Mascia L, Del Turco M, et al. Effects of recruiting maneuvers in patients with acute respiratory distress syndrome ventilated with protective ventilatory strategy. Anesthesiology 2002; 96: 795-802.

57. Patroniti N, Foti G, Cortinovis B, et al. Sigh improves gas exchange and lung volume in patients with acute respiratory distress syndrome undergoing pressure support ventilation. Anesthesiology 2002; 96: 788-794.

58. Bein T, Kuhr LP, Bele S, Ploner F, Keyl C, Taeger K. Lung recruitment maneuver in patients with cerebral injury: effects on intracranial pressure and cerebral metabolism. Intensive Care Med 2002; 28: 554-558. 